\title{
DO PLANO AO PROJETO: avaliação da transformação urbana a partir da relação entre uso do solo e transporte coletivo na cidade de Curitiba
}

\author{
Letícia Nerone Gadens \\ Universidade Federal do Paraná - UFPR \\ leticia_gadens@yahoo.com.br
}

\section{RESUMO}

Este projeto de pesquisa fundamenta-se na discussão da relação entre plano e projeto urbano, considerando o processo de construção do espaço a partir da concepção de Milton Santos. O objetivo central deste estudo consiste em avaliar como as diretrizes de planejamento influenciam o desenho urbano, partindo da hipótese de que há limitações no processo de planejamento que refletem práticas de desenho insustentáveis ao não considerar sua repercussão territorial. Assim, o aprofundamento desta discussão poderia evidenciar oportunidades de construção de espaços mais inclusivos e sustentáveis. Nesse sentido, a pesquisa volta-se a análise da cidade de Curitiba, Brasil, que teve seu planejamento fundamentado na relação entre uso do solo, sistema viário e transporte coletivo. Com base em estruturação metodológica de múltiplas técnicas, pretende-se obter como resultado uma síntese analítica, de modo a verificar a hipótese da pesquisa, contribuindo com o instrumental de planejamento e desenho urbano.

Palavras-chave: planejamento urbano; projeto urbano; desenho urbano; instrumentos urbanísticos.

\begin{abstract}
This research project is based on the discussion of the relationship between plan and urban project, considering the process of space construction from the conception of Milton Santos. The central objective of this study is to evaluate how planning guidelines influence urban design, based on the hypothesis that there are limitations in the planning process that reflect unsustainable design practices by not considering its territorial repercussion. Thus, the deepening of this discussion could highlight opportunities for building more inclusive and sustainable spaces. In this sense, the research returns to the analysis of the city of Curitiba, Brazil, whose planning was based on the relationship between land use, road system and collective transportation. Based on methodological structuring of multiple techniques, we intend to obtain as a result an analytical synthesis, in order to verify the hypothesis of the research, contributing with the instruments of urban planning and design.
\end{abstract}

Keywords: Urban planning; urban project; urban design; urbanistic tools. 


\section{INTRODUÇÃO}

Este trabalho consiste em um projeto de pesquisa que tem por fundamento a discussão da relação entre planejamento e projeto urbano, considerando o processo de construção do espaço a partir da concepção do geógrafo Milton Santos. Segundo o autor, a cidade consiste em um ambiente artificial, construído no meio antes natural, e, em seguida manipulado pelas ações sociais. Assim, a produção espacial das cidades está intimamente relacionada aos interesses dos seus agentes, envolvendo "fixos" e "fluxos". Os primeiros permitem ações que modificam o próprio local, enquanto que os segundos criam ou recriam condições ambientais e sociais, redefinindo cada lugar (Santos, 2008).

O geógrafo avança nesta reflexão propondo o conceito de espaço como conjunto indissociável do sistema de ações e objetos, os quais se influenciariam mutuamente. A partir deste subsidio teórico conceitual, esta pesquisa pretende verificar o processo de construção do espaço urbano a partir da relação entre planejamento, entendido como o "sistema de ações" e sua projeção territorial, em termos de desenho urbano, concebido como "sistema de objetos".

Assim, o objetivo central da pesquisa consiste em avaliar como as diretrizes de planejamento influenciam o desenho urbano, ou seja, a configuração espacial da cidade. Considera-se que as experiências de planejamento brasileiras se encontram, por vezes, desvinculadas de sua repercussão territorial, havendo, portanto, a necessidade de aprofundamento do debate sobre a relação entre plano e desenho urbano, o que poderia evidenciar oportunidades de construção de espaços mais inclusivos, promovendo justiça espacial. Desta forma, parte-se da hipótese de que há limitações no processo de planejamento que refletem práticas de desenho insustentáveis, ao reproduzir espacialmente condições que reforçam a segregação social e limitam a apropriação e uso de espaços urbanos.

Esta investigação adota como recorte físico de análise a cidade de Curitiba - Brasil, considerando que esta é reconhecida internacionalmente por suas práticas de urbanismo. Além disso, teve seu planejamento concebido de forma estritamente vinculado ao desenho urbano, quando propôs, em 1965, a utilização de um modelo de urbanização fundamentado na relação entre uso do solo, sistema viário e transporte coletivo, definindo setores estruturais. Essa concepção possibilitou a implantação do BRT, um sistema inovador à época, que foi reinterpretado em diversos municípios no Brasil, além de outros países (IPPUC, 2014). A idealização do BRT esteve alinhada a valores de desenvolvimento sustentável, capacidade de deslocamento e baixo custo, sendo, portanto, solução possível de aplicação em países desenvolvidos ou em desenvolvimento (Allaire, 2006).

Nesse sentido, a partir da análise deste recorte físico, pretende-se:

a) Verificar as concepções de planejamento que orientaram a conformação dos setores estruturais da cidade, os quais consistem em importantes eixos viários que comportam o sistema BRT;

b) Interpretar o desenho urbano existente nesses setores.

Dessa forma, o estudo dessa experiência empírica tem por objetivo contribuir com o debate sobre 0 instrumental de planejamento e desenho urbano, de modo a estabelecer reflexões sobre sua articulação, além de identificar possibilidades que resultem em espaços urbanos mais sustentáveis. Neste caso, o conceito de sustentabilidade apresenta-se em seu sentido amplo, considerando a produção de um espaço que permita menores impactos ambientais e também a estruturação de cidades mais inclusivas, ou seja, com menor segregação social. Portanto, na presente pesquisa o termo "cidade sustentável" estará concentrado no espectro da relação social-eco-econômico (Jabareen, 2006).

Assim, este trabalho orienta-se pela discussão das limitações do planejamento urbano, tendo em vista que, por vezes, se encontra desvinculado dos seus resultados espaciais, na escala de desenho urbano. Considera-se, portanto, o urbanismo enquanto uma modalidade de planejamento físico, que privilegia o plano, a forma e o desenho. Nesse sentido, esse projeto de pesquisa pretende discutir, a partir da base conceitual de Milton Santos, a relação entre sistema de ações e objetos, de modo a contribuir com a reflexão sobre a prática do planejamento enquanto meio de alteração física do espaço urbano.

\section{PLANO E PROJETO URBANO}


Considerando o objetivo desta pesquisa, faz-se um ensaio inicial sobre a temática, buscando compreender que a produção do espaço urbano envolve diferentes escalas de atuação, as quais deveriam complementarse e articular-se, em conjunto. A primeira delas, seria a escala de apreensão da cidade em seu sentido mais amplo, correspondendo ao planejamento urbano. O nível de apreensão do espaço em relação a proporção humana, estaria relacionado ao tratamento espacial na escala do desenho urbano. Por fim, a categoria intermediária poderia corresponder a uma modalidade mais recente de intervenção, sobretudo na realidade brasileira, que consiste na definição do projeto urbano.

Assim, essa investigação situa-se em um contexto de discussão entre plano e projeto, considerando que o aprofundamento do debate sobre essa relação pode contribuir com a construção de uma metodologia que considere a intervenção territorial sob uma perspectiva holística de cidade. Ressalta-se que não se pretende estabelecer essa discussão em um caráter dual que identifique o que é um bom planejamento, pois, ao se estabelecer uma reflexão dessa natureza, cada resposta irá depender de quem pergunta ou de quem responde, considerando a existência de variações de acordo com os diferentes grupos de interesse: 0 governante, o planejador, ou os grupos sociais envolvidos (Limonad, 2015). Nesse sentido, torna-se recorrente a necessidade do aprofundamento da discussão que considere as formas e modalidades de se planejar de modo que a espacialização territorial de suas propostas gere relações que contribuam para cidades mais sustentáveis e inclusivas.

Nas últimas décadas, a promoção de um futuro urbano mais sustentável ganhou relevância, apresentando como resultado uma série de conceitos voltados a promoção da sustentabilidade (Fu; Zhang, 2016). Assim, diversos princípios e estratégias foram introduzidos para manter a prática do planejamento e do desenho urbano alinhados à noção atualizada de sustentabilidade (Walter; Arkin; Crenshaw, 1992). Além disso, uma aproximação crítica do tema demonstra uma falta de concordância sobre quais seriam as práticas mais desejáveis de planejamento e desenho urbano nesse contexto (Williams; Burton; Jenks, 1996; Hildebrand, 1999).

Recentemente, na Conferência das Nações Unidas sobre Moradia e Desenvolvimento Urbano Sustentável, denominada Habitat III, foi promulgada a Nova Agenda Urbana que tem por objetivo orientar a promoção do desenvolvimento urbano nas próximas décadas. Consta como base nessa discussão, dentre outras questões, o entendimento de que as cidades devem ser inclusivas, partindo da premissa de que a urbanização pode ser vista como uma oportunidade para o desenvolvimento sustentável. (ONU, 2016). Nesse sentido, implementar a Nova Agenda Urbana significa estabelecer a provisão adequada de bens comuns, incluindo padrões eficientes de desenho, em uma relação intrínseca entre planejamento e projeto.

Verifica-se, no entanto, que há uma falta de identidade disciplinar no planejamento urbano, por meio da confusão entre este e o urbanismo, a ciência política, a gestão pública, entre outros. Este fato, tende a limitar sua capacidade de desenvolver uma reflexão explicativa e analítica, em dimensão ampliada, com relação as suas práticas espaciais (Gualini, 2005). Nesse sentido, resulta daí uma tendência comum de subordinar as questões de planejamento à uma perspectiva técnica, prescritiva e normativa, sem refletir sobre seu papel na sociedade e na produção do espaço social (Limonad, 2015).

Nesse contexto, Limonad (2015) argumenta que há diferentes abordagens de planejamento, enquanto prática de intervenção no território e processo de produção de cidade. A autora, com base nas vertentes propostas por Yiftachel (1989), identifica diferenças entre o planejamento e o urbanismo mediante a sistematização de modelos e teorias que apresentam ênfases distintas, em termos de abordagem analítico conceitual, processual e de desenho. Essas aproximações estão ora mais voltadas à própria concepção do plano, ora orientadas à consecução de um projeto urbano, revelando a relação dual entre plano e projeto.

Há, de modo geral, divergências e discussões enquanto a prática e campo de atuação do planejamento e desenho urbano. Gunder (2011) argumenta que os produtos do urbanismo e do desenho contemporâneos, domínio de arquitetos e de urbanistas, estão voltados a atender os interesses globalizados do setor privado, do capital coorporativo e à agenda neoliberal, em detrimento da satisfação do bem comum ou de um interesse público mais amplo. Por outro lado, o planejamento, em princípio, teria uma preocupação com valores humanos e não-mercantis, em razão de sua fundamentação enquanto prática de interesse público, compreendendo contribuições e trabalho de distintos campos profissionais. O autor entende, ainda que, uma forma de trazer o desenho urbano e o urbanismo para um campo comum seria a permanência destes como um subcampo do planejamento urbano e regional, preocupados com a forma, a estética e a habitabilidade. Assim, contribuiriam para os imperativos de equidade, justiça social e sustentabilidade, que 
prevaleceriam sobre as metas de lucratividade do desenho urbano, urbanismo e planejamento (Gunder, 2011).

Jacobs (2000) já destacava que os arquitetos se importavam prioritariamente com as edificações, sem perceber contextos sociais mais amplos e as implicações sociais de seus projetos. Enquanto que os planejadores, dada a interdisciplinaridade da prática e reflexão, tendem a enfatizar várias metas e critérios, bem como um processo analítico e colaborativo em seus planos. Portanto, se faz relevante o estudo do espaço sob a ótica das relações entre os conceitos, instrumentos e processos que subsidiaram o seu planejamento. Batty (2013) sugere que para entender as cidades é necessário observa-las não apenas como simples lugares no espaço, mas como sistemas de redes e fluxos. Para entender o espaço, é preciso entender os fluxos, e para entender os fluxos, é preciso entender as redes - a relação entre objetos que compreende o sistema da cidade. A compreensão dessa rede pode enfatizar uma noção relevante para o futuro da pesquisa sobre planejamento e projeto urbano, partindo da assertiva de que o espaço da cidade é resultado de uma ação coletiva.

Nesse campo de discussão, a compreensão conceitual de desenho urbano também é relevante, enquanto resultado espacial de ações, planejadas ou não. Nesse sentido, embora a forma urbana seja de difícil definição, é útil operacionalizar o termo buscando sua aplicação para a discussão da produção do espaço. Geralmente, a forma é resultado da composição de características relacionadas aos padrões de uso do solo, sistema de transporte e desenho urbano (Handy, 1996). Como campo disciplinar do conhecimento, o desenho urbano estaria entre a escala da arquitetura e do planejamento, tratando a dimensão físico ambiental da cidade, enquanto um conjunto de sistemas físico-espaciais e sistemas de atividades que interagem com a população por meio de suas vivências e percepções cotidianas (Del Rio, 1990).

No âmbito da discussão do desenho urbano, embora existam divergências conceituais no estudo acadêmico sobre o tema, adota-se os conceitos pressupostos a partir da década de 1960, sobretudo por autores como Jacobs (2000), Gehl (2006), Del Rio (1990), Lynch (1997) que se debruçavam sobre o estudo do desenho enquanto meio de produção do espaço em estreita relação com a escala humana, considerando que essa leitura possui convergência com princípios de padrões sustentáveis de ocupação do território. Nesse sentido, tornam-se relevantes elementos como a densidade e a diversidade de usos, apropriação dos espaços públicos, o estimulo ao movimento das pessoas, as relações de vizinhança, entre outros.

Nesse sentido, o new urbanism, aproximação neotradicionalista de planejamento, fundamenta-se em estratégias de desenho baseadas em formas urbanas tradicionais que contribuam para evitar 0 espraiamento e o declínio dos centros, construindo ou reconstruindo vizinhanças e cidades (Jabareen, 2006). Sugere, portanto, certos conceitos de desenho sustentável, como o incentivo a deslocamentos a pé, alta densidade residencial, mistura de usos (residenciais, comerciais, institucionais, entre outros (Audirac; Shermyen, 1994; Nasar, 2003). Outro princípio aliado a esta corrente neotradicionalista consiste no trasit oriented development - TOD, que parte da premissa de que a concentração de pessoas e atividades diversificadas no entorno de serviços de transporte permite a convergência de demandas, maximizando a eficiência do sistema de transporte coletivo e reduzindo a necessidade de deslocamentos motorizados (Newman, 1996; Lund; Cervero; Wilson, 2004; Jabareen, 2006; Litman, 2016). Portanto, verifica-se que algumas questões são relevantes na prática do desenho urbano enquanto produção de espaços sustentáveis, como diversidade, usos mistos, densidade, entre outros. Assim, os critérios de análise da presente pesquisa tomam por base a conceituação de Jabareen (2006) enquanto o estudo de formas urbanas sustentáveis.

Situado entre esses dois campos de atuação, o do planejamento e o do desenho urbano, a intervenção por meio de projetos adquiriu importância nas últimas décadas, inicialmente como forma de oposição ao planejamento tradicional. Essa prática, que articula projetos, de maior ou menor escala, à um plano urbano, concretiza-se sobre uma parte do território, articulando-se com uma visão global de cidade (Lungo, 2004). Esta forma de intervenção no espaço, que estabelece uma nova relação entre plano e projeto, é oportunizada com a perspectiva de mudança do papel do Estado, que a partir da década de 1980 passa a se orientar para uma nova agenda que objetiva a eficiência na gestão pública (Rezende, 2002).

No contexto brasileiro, a chamada Reforma do Estado, a partir do enfraquecimento do governo, foi vinculada à mudança do regime político, quando, na década de 1980, a cidade voltou a ser gerida em um modelo democrático. Essa situação foi acompanhada de significativo processo de reformulação política, que fortaleceu o presidencialismo, transformou as instituições e promoveu a descentralização do Estado, 
apresentando consequências na lógica de urbanização da América Latina, o que contribuiu para a formulação de novos instrumentos, formas de financiamento e atuação sobre o espaço urbano (Carrión, 2007). Nesse contexto, a elaboração do plano, a partir de procedimentos racionais, gerando espaços controlados e ordenados, perdeu a relação de precedência frente ao projeto urbano (Maleronka, 2010).

Assim, a discussão que se pretende desenvolver com essa pesquisa, fundamentada na relação entre plano e projeto e, tendo em vista o novo contexto de atuação do Estado, considera o referencial conceitual de grandes projetos urbanos (GPUs), os quais tem sido frequentemente utilizados, a despeito de suas distintas bases conceituais e instrumentais, como meio de produção do espaço urbano, estabelecendo novas abordagens na relação entre plano e projeto. Por se tratar de um conceito ainda em formação, diversas dimensões de caracterização de GPUs podem ser encontrados na literatura. Assim, podem ser entendidos como operações físicas que envolvem, em geral, consideráveis somas financeiras e promovem alterações expressivas no espaço urbano, caracterizando-se como importantes intervenções nas cidades contemporâneas (Hardt et. al., 2008).

Ultramari e Rezende (2007) argumentam que os GPUs correspondem a instrumentos de política pública cuja escala projetual se distingue do entorno, sendo capazes de reproduzir impactos para além dos seus limites imediatos. Além disso, também podem ser interpretados como iniciativas de renovação urbana, que se concentram em determinados setores da cidade e envolvem agentes públicos e privados, cujos investimentos em intervenções seguem diretrizes de um plano urbanístico apoiado no redesenho do espaço urbano, em especificidades legais ou em novas articulações institucionais e formas de gestão (Someck; Campos Neto, 2005). Assim, a despeito de uma visão de exaltação ou de um posicionamento de censura com relação aos GPUs, a produção acadêmica sobre o tema tem evidenciado o seu uso enquanto novas formas de produção do espaço. Portanto, se por um lado são verificados limites e falta de consenso sobre o conceito e suas implicações, por outro, tem-se insinuações de tendências a serem consideradas no planejamento urbano contemporâneo (Gadens; Hardt; Frey, 2012).

\section{CENÁRIO DE ANÁLISE}

A história do planejamento urbano no Brasil é caracterizada por diferentes abordagens sobre o pensar a cidade e propor diretrizes e ações sobre o território. Os primeiros planos, reconhecidos como "Planos de embelezamento" e realizados no período de 1875 a 1930, provinham da tradição europeia e tinham por objetivo principal sanear e embelezar a cidade, propondo o alargamento de vias, erradicação de ocupações de baixa renda nas áreas mais centrais e implementação de infraestruturas, especialmente de saneamento e ajardinamento de parques e praças. A partir da década de 1930, surgem os chamados "Planos de conjunto", que se dedicavam a toda a cidade, buscando a integração das diretrizes urbanísticas em todo o território municipal. Essa fase foi sucedida pela proposição dos "Planos de desenvolvimento integrado" (1965-1971), caracterizados pela incorporação ao plano de aspectos sociais e econômicos, além dos físicos territoriais. A partir de 1971, surgem os denominados "Planos sem mapas", que passam da complexidade e do rebuscamento técnico anterior para a elaboração de planos sem espacialização territorial e sem diagnósticos ou com a presença de diagnósticos reduzidos. (Villaça, 1999; Leme, 1999). Ao longo dessas distintas fases, a proposição técnica sempre foi uma vertente predominante no processo de planejar a cidade. Segundo Villaça (1999), diversos desses planos pautaram-se por interesses que incluíam mais a proteção do valor de propriedades fundiárias e a possibilidade de extração de lucros por meio da produção imobiliária. Além disso, muitos desses planos não foram implantados em sua totalidade.

A Constituição Federal de 1988 foi relevante ao estabelecer por meio dos artigos 182 e 183 o marco da política urbana no Brasil, lançando, desta forma, uma nova ordem jurídica e urbanística, a qual foi consolidada, anos mais tarde, com a aprovação da Lei Federal n. ${ }^{\circ} 10.257 / 2001$, denominada Estatuto da Cidade. Este diploma legal, ao definir as diretrizes gerais da política urbana, fez a previsão de uma série de instrumentos voltados ao cumprimento da a função social da propriedade. Nesse projeto de pesquisa, há especial interesse na análise de dois destes instrumentos: o zoneamento e a operação urbana consorciada, considerando que ambos promovem a articulação entre o plano e o desenho urbano.

O zoneamento, já utilizado em outros planos elaborados anteriormente ao Estatuto da Cidade, consiste em um instrumento amplamente aplicado no planejamento urbano brasileiro, sobretudo nos Planos Diretores, e que prevê a divisão da cidade em áreas sobre as quais incidem diretrizes de uso e ocupação do solo específicas. Assim, utiliza-se do controle de dois elementos principais: o uso do solo, definindo quais atividades serão ou não permitidas em determinadas regiões, e a ocupação, considerando a densidade 
construtiva permitida e o tamanho dos lotes a serem gerados, em acordo com a infraestrutura disponível, questões ambientais, entre outros fatores.

Por outro lado, as operações urbanas consorciadas (OUCs) consistem em um conjunto de intervenções coordenadas pelo poder público municipal, com a participação de diversos atores (proprietários, moradores, investidores e usuários), com o objetivo viabilizar transformações urbanísticas estruturais. As primeiras experiências na aplicação do instrumento foram realizadas em São Paulo, na década de 1990. Neste sentido, foram concebidas a partir do conceito de solo criado, com a previsão de aumento de índices construtivos e cobrança de contrapartidas, sem haver, no entanto, um projeto definido para a transformação do território (Maleronka, 2012).

Com o advento do Estatuto da Cidade, em 2001, houve uma reformulação na proposição de operações urbanas adequadas à nova realidade jurídica e urbanística. As experiências implementadas a partir deste novo marco jurídico, podem ser caracterizadas pela aplicação do Certificado de Potencial Adicional de Construção (CEPAC), cuja utilização otimizou a cobrança de contrapartidas, permitindo, inclusive, a antecipação de receitas para o poder público (Maleronka, 2012). No entanto, a dimensão de projeto dessas operações, no que tange às intenções de transformação do território, permaneceu débil. A experiência geral de implantação desse instrumento vem demonstrando a importância da relação entre o poder público e o setor privado na transformação do espaço urbano. Por outro lado, sua aplicação tem evidenciado o estabelecimento de operações imobiliárias altamente lucrativas, que geram por consequência, espaços gentrificados e segregados no tecido urbano.

$\mathrm{Na}$ cidade de Curitiba observa-se a utilização de ambos os instrumentos, sendo que a aplicação do zoneamento se encontra mais consolidada, enquanto que a OUC está sendo utilizada pela primeira vez, em um projeto de reconversão de uma estrutura rodoviária em via urbana e metropolitana. O planejamento urbano da cidade foi concebido, a partir do Plano Preliminar de Urbanismo, com um modelo linear de expansão urbana com o objetivo de orientar o processo de crescimento de forma ordenada, integrando sistema viário, transporte coletivo e uso do solo (IPPUC, 1965). Assim, as diretrizes de planejamento configuraram um desenho urbano que resultou em maior densidade de ocupação ao longo dos eixos estruturais, nos quais se encontra o espaço destinado para a circulação do sistema BRT.

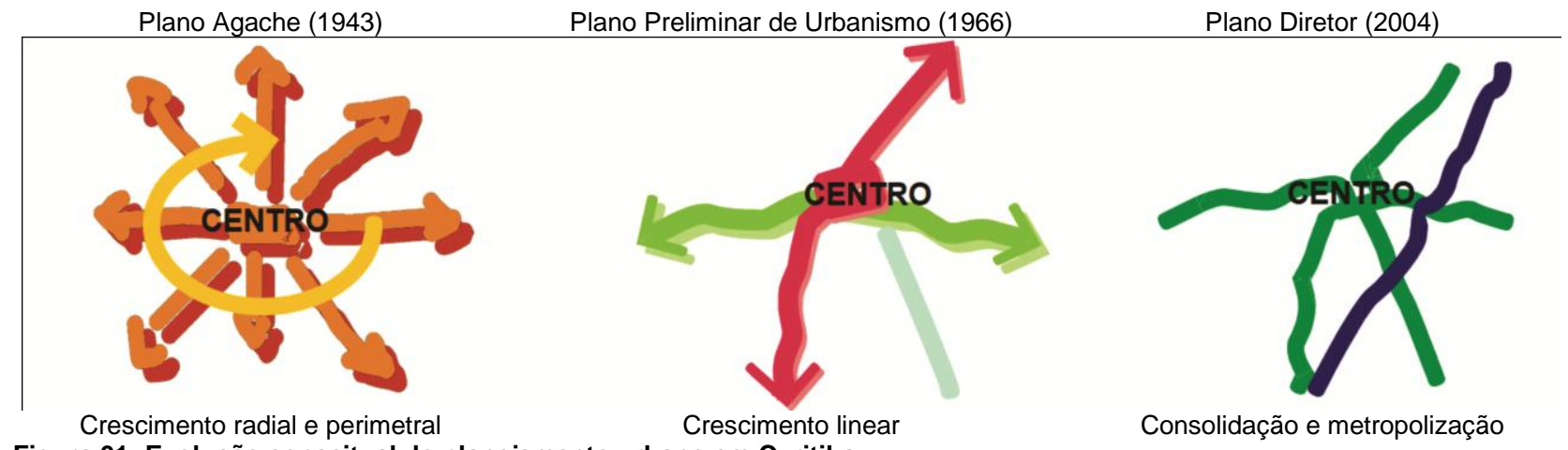

Figura 01: Evolução conceitual do planejamento urbano em Curitiba.

Elaborado com base em IPPUC (2014). 


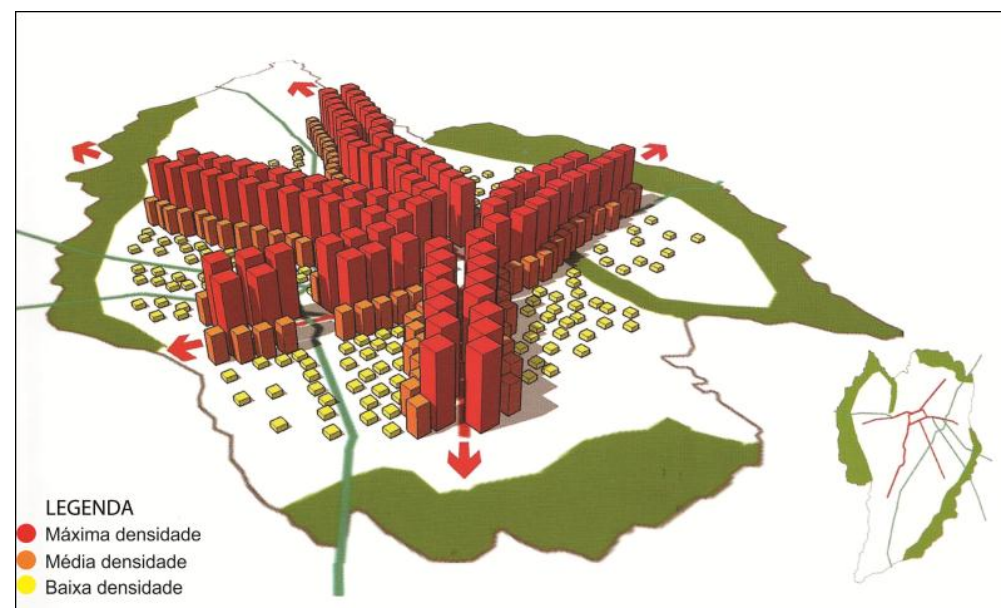

Figura 02: Concepção dos setores estruturais por meio da articulação do sistema viário, transporte coletivo e uso do solo. Dudeque (2010).

Recentemente, a esses setores estruturais, somou-se o processo de reconversão funcional da antiga rodovia BR 166 em nova via urbana, configurando-se um importante eixo de conexão no sentido norte-sul, inclusive em escala metropolitana. A consolidação desse processo pode permitir a integração de 23 bairros da cidade, estruturando o crescimento da sua porção leste. A implantação deste projeto, intitulado "Linha Verde", está sendo viabilizado por meio da aplicação do instrumento operação urbana consorciada, proposto em 2011, o qual tem por objetivo captar recursos para a complementação das obras de sistema viário e transporte, ofertar espaços de uso público e promover a requalificação urbanística e a regularização fundiária (Curitiba, 2011).

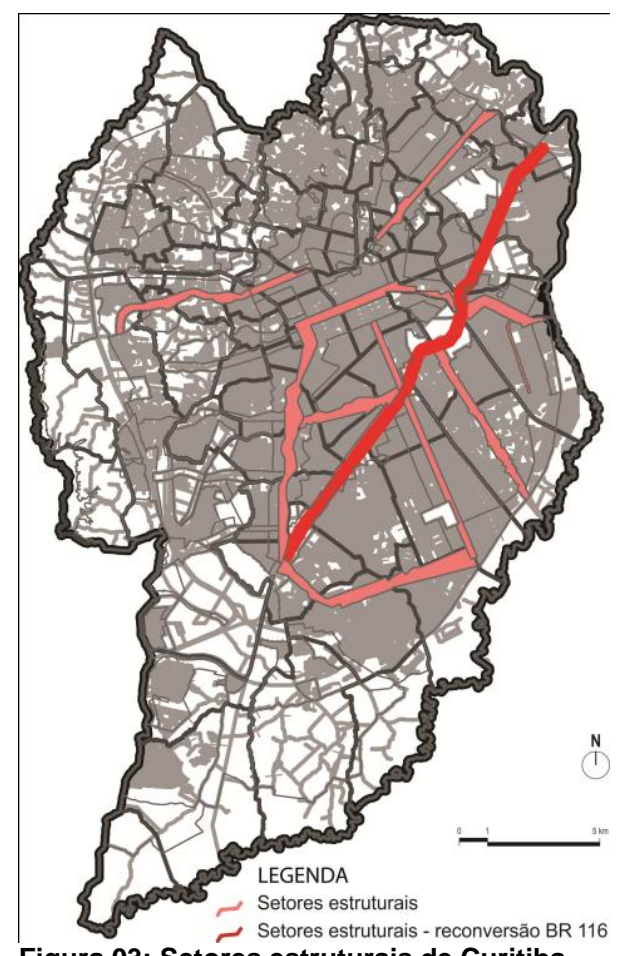

Figura 03: Setores estruturais de Curitiba.

Elaborado com base em IPPUC (2014). 


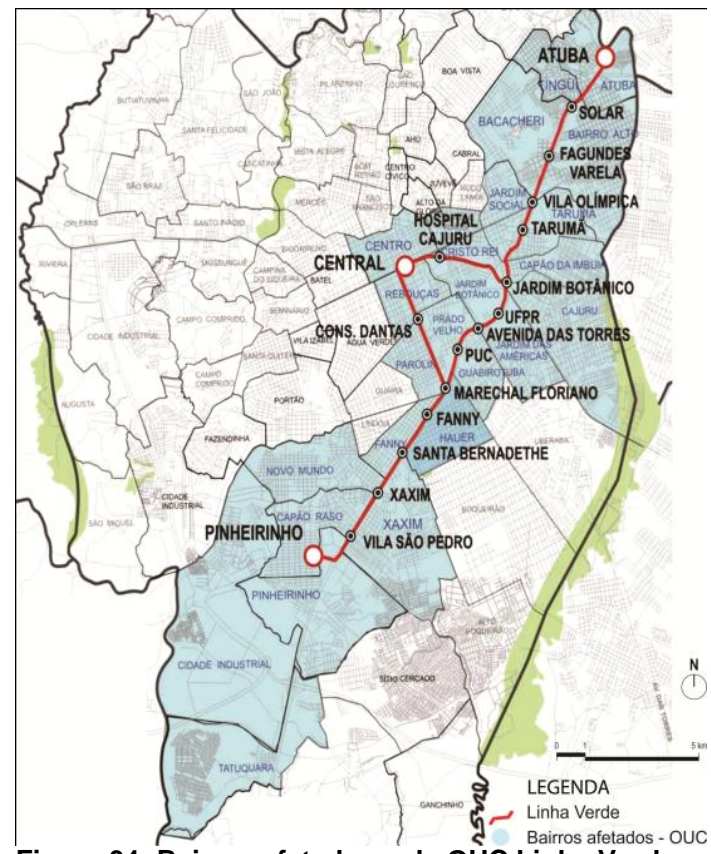

Figura 04: Bairros afetados pela OÚC Linha Verde.

Elaborado com base em IPPUC (2014).

Na recente revisão do Plano Diretor, aprovado em 2015, esses eixos estruturais permanecem com a função de estruturação do crescimento urbano, caracterizando-se como corredores de ocupação mista de alta densidade. Além disso, há a intenção de estruturação territorial no sentido leste-oeste a partir da proposição de novos eixos de adensamento, que devem atuar de forma complementar aos eixos estruturais, com ocupação mista de média densidade (IPPUC, 2015).

A partir desse contexto urbano, é possível evidenciar a existência de uma lógica de construção do espaço urbano a partir de uma estreita relação entre uso do solo e transporte coletivo. Portanto, considerando o objetivo central da pesquisa, que consiste em avaliar como as diretrizes de planejamento influenciam o desenho urbano, considera-se dois recortes espaciais de estudo, na cidade de Curitiba:

a) Compartimentos urbanos consolidados ou em processo de consolidação, como os setores estruturais da cidade, cujo planejamento centrou-se na utilização instrumental do zoneamento;

b) Compartimentos urbanos em processo de reconversão, como o projeto da Linha Verde, cujo planejamento está apoiado na utilização do instrumento OUC.

Esses recortes devem levar em consideração a distinção temporal, conceitual e instrumental que concebeu o planejamento e, consequentemente, suas repercussões espaciais, em termos de desenho urbano. Portanto, a delimitação temporal para as análises considera:

a) Período de 1966 - 2016, para os compartimentos urbanos consolidados ou em processo de consolidação, tendo em vista que, é a partir de 1966, com a aprovação do Plano Preliminar de Urbanismo, que se estrutura a proposta de configuração dos eixos estruturais da cidade;

b) Período de 2004 - 2016, para os compartimentos urbanos em processo de reconversão, considerando a revisão do Plano Diretor de 2004, quando se adequou o planejamento às premissas do Estatuto da Cidade, incorporando novos instrumentos urbanísticos como a Operação Urbana Consorciada.

Assim, a estruturação do espaço de Curitiba evidencia possibilidades de discussão da relação entre plano e projeto, considerando que, a despeito das distinções anteriormente mencionadas, os casos selecionados para estudo evidenciam dois importantes momentos de inflexão urbana, na medida em que permitiram a promoção de ostensivas alterações no território, seja por meio da consolidação de setores estruturais que orientaram o desenvolvimento da cidade; ou por meio de um processo de reconversão, que ainda em curso, poderá potencializar a consolidação de um novo eixo urbano.

Essa discussão também se faz oportuna em virtude da atual conjuntura de Curitiba, que teve seu Plano Diretor revisado e aprovado recentemente, com o objetivo de orientar e controlar o desenvolvimento 
integrado, fundamentando-se nas premissas do Estatuto da Cidade. Além disso, encontra-se em tramitação a proposta de revisão do zoneamento de uso e ocupação do solo. Esta proposta prevê adequações em relação ao zoneamento atual, merecendo destaque a extensão de setores conectores para leste, o estímulo de adensamento nos eixos do sentido leste-oeste; a implantação de habitação de interesse social em áreas dotadas de infraestrutura; a criação de setor especial de saneamento ambiental, com instrumentos que visam a ocupação controlada destas áreas.

\section{ABORDAGEM METODOLÓGICA}

Este estudo é de natureza aplicada tendo em vista que se volta à utilização do conhecimento em situação prática (Silva; Menezes, 2005), visando o aprofundamento da discussão sobre as abordagens de planejamento e desenho urbano. Também se caracteriza como uma pesquisa exploratória a medida em que tem como intuito criar familiaridade com o problema apresentado (Gil, 2002). Apoia-se em método dedutivo a partir da observação e interpretação dos critérios de análise aplicados.

Assim, os procedimentos e técnicas que devem fundamentar o estudo em questão constituem-se, primordialmente de: pesquisa bibliográfica, interpretação documental e investigação em campo, sendo metodologicamente estruturado em cinco fases principais:

a) Estruturação do embasamento teórico e conceitual sobre planejamento, projeto e desenho urbano, a partir de princípios de sustentabilidade; esta fase de caráter essencialmente exploratório (Gil, 2002), visa à sistematização dos conceitos que devem subsidiar as análises a serem realizadas;

b) Caracterização do recorte físico e temporal, com vistas à contextualização geral dos exemplos selecionados para o estudo;

c) Análise do "sistema de ações" (Santos, 2008), que corresponde ao conjunto de conceitos, diretrizes e instrumentos que subsidiaram o planejamento urbano;

d) Análise do "sistema de objetos" (Santos, 2008), por meio da identificação do desenho resultante a partir de critérios que evidenciam práticas de sustentabilidade urbana;

e) Discussão sobre os resultados encontrados, revelando a natureza aplicada da pesquisa (Silva; Menezes, 2005), com ênfase na relação sistêmica plano e projeto.

A seguir, apresenta-se o protocolo de pesquisa, demonstrando um detalhamento de cada uma das fases:

\begin{tabular}{|c|c|c|c|c|c|}
\hline FASES & METODOS & TECNICAS & DADOS & FONTES & RESULTADOS \\
\hline \multicolumn{6}{|c|}{ EMBASAMENTO TEÓRICO CONCEITUAL } \\
\hline $\begin{array}{l}\text { Elaboração do } \\
\text { referencial teórico }\end{array}$ & Exploratório & $\begin{array}{l}\text { Pesquisa } \\
\text { bibliográfica }\end{array}$ & $\begin{array}{l}\text { Conceitos e discussões } \\
\text { sobre plano, projeto e } \\
\text { desenho urbano }\end{array}$ & $\begin{array}{l}\text { Livros, artigos } \\
\text { científicos, } \\
\text { trabalhos } \\
\text { acadêmicos e } \\
\text { outras } \\
\text { referências }\end{array}$ & $\begin{array}{l}\text { Fundamentação } \\
\text { teórico-conceitual } \\
\text { para embasamento } \\
\text { da pesquisa }\end{array}$ \\
\hline \multicolumn{6}{|c|}{ CARACTERIZAÇÃO RECORTE FISICO E TEMPORAL } \\
\hline $\begin{array}{l}\text { Contextualização } \\
\text { do objeto de } \\
\text { estudo }\end{array}$ & $\begin{array}{l}\text { Exploratório e } \\
\text { descritivo }\end{array}$ & $\begin{array}{l}\text { Pesquisa } \\
\text { bibliográfica e } \\
\text { documental }\end{array}$ & $\begin{array}{l}\text { Contextualização na escala } \\
\text { municipal e específica dos } \\
\text { recortes de estudo }\end{array}$ & $\begin{array}{l}\text { Livros, artigos } \\
\text { científicos, } \\
\text { trabalhos } \\
\text { acadêmicos, } \\
\text { mapas } \\
\text { temáticos, } \\
\text { informações } \\
\text { institucionais e } \\
\text { legais }\end{array}$ & $\begin{array}{l}\text { Caracterização dos } \\
\text { planos e projetos }\end{array}$ \\
\hline \multicolumn{6}{|c|}{ ANÁLISE - SISTEMA DE AÇŌES } \\
\hline $\begin{array}{l}\text { Identificação e } \\
\text { avaliação dos } \\
\text { conceitos, } \\
\text { diretrizes e } \\
\text { instrumentos de } \\
\text { planejamento }\end{array}$ & $\begin{array}{l}\text { Exploratório, } \\
\text { descritivo e } \\
\text { analítico }\end{array}$ & $\begin{array}{l}\text { Pesquisa } \\
\text { bibliográfica e } \\
\text { documental }\end{array}$ & $\begin{array}{l}\text { Concepção, conceitos, } \\
\text { abordagens e instrumentos } \\
\text { de planejamento utilizados }\end{array}$ & $\begin{array}{l}\text { Livros, artigos } \\
\text { científicos, } \\
\text { trabalhos } \\
\text { acadêmicos, } \\
\text { informações } \\
\text { institucionais e } \\
\text { legais }\end{array}$ & $\begin{array}{l}\text { Caracterização da } \\
\text { concepção de } \\
\text { planejamento } \\
\text { enquanto proposição } \\
\text { de desenho urbano }\end{array}$ \\
\hline \multicolumn{6}{|c|}{ ANÁLISE - SISTEMA DE OBJETOS } \\
\hline $\begin{array}{l}\text { Reconhecimento e } \\
\text { análise do } \\
\text { desenho urbano }\end{array}$ & $\begin{array}{l}\text { Exploratório, } \\
\text { descritivo e } \\
\text { analítico }\end{array}$ & $\begin{array}{l}\text { Pesquisa } \\
\text { documental e } \\
\text { de campo }\end{array}$ & $\begin{array}{l}\text { a) Compacidade } \\
\text { b) Densidade } \\
\text { c) Usos mistos } \\
\text { d) Diversidade }\end{array}$ & $\begin{array}{l}\text { Base } \\
\text { cartográfica, } \\
\text { fotos aéreas, } \\
\text { informações } \\
\text { institucionais e } \\
\text { legais e } \\
\text { pesquisa de } \\
\end{array}$ & $\begin{array}{l}\text { Caracterização do } \\
\text { desenho urbano a } \\
\text { partir da análise de } \\
\text { critérios de formas } \\
\text { urbanas voltadas à } \\
\text { sustentabilidade }\end{array}$ \\
\hline
\end{tabular}




\begin{tabular}{|c|c|c|c|c|c|}
\hline & & & & campo & \\
\hline \multicolumn{6}{|c|}{ SÍNTESE ANALÍTICA } \\
\hline $\begin{array}{l}\text { Discussão } \\
\text { sintético analítica } \\
\text { com vistas as } \\
\text { questões que } \\
\text { estruturam a } \\
\text { pesquisa }\end{array}$ & $\begin{array}{l}\text { Sintético } \\
\text { analítico }\end{array}$ & $\begin{array}{l}\text { Síntese dos } \\
\text { resultados } \\
\text { obtidos nas } \\
\text { etapas } \\
\text { anteriores }\end{array}$ & $\begin{array}{l}\text { Relações entre dados } \\
\text { (sistema de ações e sistema } \\
\text { de objetos) }\end{array}$ & $\begin{array}{l}\text { Informações } \\
\text { resultantes das } \\
\text { etapas } \\
\text { anteriores }\end{array}$ & $\begin{array}{l}\text { Contribuições para as } \\
\text { discussões das } \\
\text { abordagens e } \\
\text { instrumentos de } \\
\text { planejamento e } \\
\text { projeto urbano }\end{array}$ \\
\hline
\end{tabular}

Quadro 01: Protocolo de pesquisa.

Elaborado com base nos objetivos do estudo.

Nesse sentido, a partir da estruturação do protocolo de pesquisa, foram elaborados os constructos, como critérios que objetivam a definição de medidas operacionais para as questões que estão sendo estudadas (Yin, 1994). O Quadro 02 apresenta os constructos das principais variáveis de análise da presente pesquisa.

\begin{tabular}{|c|c|c|c|c|c|c|}
\hline \multicolumn{2}{|c|}{ VARIÁVEIS } & QUESTÕES & $\begin{array}{l}\text { ESTRATÉGIAS } \\
\text { DE ANÁLISE } \\
\text { (O QUE MEDIR) }\end{array}$ & $\begin{array}{l}\text { UNIDADES DE } \\
\text { MEDIÇÃO }\end{array}$ & $\begin{array}{l}\text { UNIDADES DE } \\
\text { OBSERVAÇÃOO }\end{array}$ & $\begin{array}{l}\text { TIPOLOGIA DE } \\
\text { ANÁLISE }\end{array}$ \\
\hline 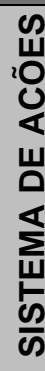 & Planejamento & $\begin{array}{l}\text { Quais conceitos, } \\
\text { diretrizes e } \\
\text { instrumentos foram } \\
\text { utilizados para } \\
\text { viabilizar o desenho } \\
\text { urbano que } \\
\text { estruturou, } \\
\text { morfologicamente, a } \\
\text { cidade de Curitiba? }\end{array}$ & $\begin{array}{l}\text { Conceitos } \\
\text { Instrumentos } \\
\text { Diretrizes }\end{array}$ & $\begin{array}{l}\text { Concepção de } \\
\text { planejamento }\end{array}$ & $\begin{array}{l}\text { Pesquisa } \\
\text { documental, } \\
\text { informações legais } \\
\text { e institucionais }\end{array}$ & Qualitativa \\
\hline \multirow{4}{*}{ 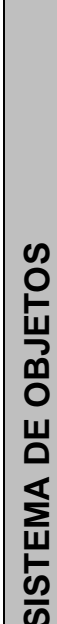 } & \multirow[t]{4}{*}{ Projeto urbano } & \multirow{4}{*}{$\begin{array}{l}\text { a) Como a } \\
\text { concepção de } \\
\text { planejamento se } \\
\text { reproduziu no } \\
\text { espaço urbano? } \\
\text { b) A fundamentação } \\
\text { do desenho urbano } \\
\text { no tripé uso do solo, } \\
\text { sistema viário e } \\
\text { transporte coletivo } \\
\text { gerou quais padrões } \\
\text { de espaços } \\
\text { urbanos? }\end{array}$} & Compacidade & $\begin{array}{l}\text { a) Vazios urbanos } \\
\text { b) Estrutura da } \\
\text { retícula urbana }\end{array}$ & \multirow{4}{*}{$\begin{array}{l}\text { Pesquisa } \\
\text { documental } \\
\text { (especialmente } \\
\text { mapas e fotos } \\
\text { aéreas) e de } \\
\text { campo }\end{array}$} & \multirow{4}{*}{$\begin{array}{l}\text { Espacial } \\
\text { (informações } \\
\text { reproduzidas no } \\
\text { território de estudo, } \\
\text { buscando } \\
\text { identificar padrões } \\
\text { de desenho } \\
\text { urbano) }\end{array}$} \\
\hline & & & Densidade & $\begin{array}{l}\text { a) Coeficiente de } \\
\text { aproveitamento } \\
\text { (permitido e } \\
\text { utilizado) } \\
\text { b) Unidades } \\
\text { habitacionais } \\
\text { c) População }\end{array}$ & & \\
\hline & & & Usos mistos & $\begin{array}{l}\text { a) Tipologia de } \\
\text { usos existentes }\end{array}$ & & \\
\hline & & & Diversidade & $\begin{array}{l}\text { a) Valor do solo } \\
\text { b) Rendimento } \\
\text { população } \\
\text { residente } \\
\text { c) Localização da } \\
\text { produção de HIS }\end{array}$ & & \\
\hline
\end{tabular}

Quadro 02: Constructos principais do estudo.

Elaborado com base no protocolo de pesquisa.

\section{RESULTADOS ESPERADOS}

A partir do desenvolvimento desse projeto de pesquisa pretende-se responder ao seu objetivo central, que consiste em avaliar como as diretrizes de planejamento influenciam o desenho urbano, configurando espacialmente a cidade. A síntese analítica pretende sistematizar a discussão dos resultados a serem obtidos, de modo a verificar a hipótese da pesquisa de que há limitações no processo de planejamento, que não consideram o território de intervenção, na escala do desenho urbano. Assim, suas ações acabam por reforçar padrões de segregação social e geração de espaços insustentáveis.

Portanto, ao final da pesquisa, pretende-se desenvolver reflexões que permitam o reconhecimento de abordagens metodológicas capazes de articular a relação entre plano e projeto como instrumental de análise e intervenção no espaço urbano, capaz de responder às dinâmicas e complexidades da cidade contemporânea. Ainda que a partir de análise sobre um estudo de caso específico, considera-se que há 
premissas que podem ser universais na discussão sobre novos instrumentais de planejamento, que resultem em transformações territoriais efetivas no sentido de contribuir com o fomento da justiça espacial, reduzindo segregações urbanas.

Nesse sentido, este estudo pretende contribuir com a reflexão sobre a articulação entre plano e projeto, identificando possibilidades de melhor associação dessas duas escalas, além de contribuir com sugestões ao instrumental urbanístico. Assim, a partir da análise do estudo de caso, pretende-se aportar contribuição ao debate científico sobre planejamento, projeto e desenho urbano, considerando a necessidade de proposição de instrumentos que permitam reconhecer, de forma apropriada, os resultados territoriais, auxiliando, nesse sentido, para a construção de espaços urbanos funcionais, inclusivos e sustentáveis.

Dessa forma, considera-se que diferentes instrumentos urbanísticos podem resultar em distintas formas de análise e intervenção territorial, sendo mais ou menos adequados a gerar respostas eficientes às dinâmicas urbanas que se apresentam na cidade contemporânea, caracterizada por constantes mudanças e cenários de incertezas. Nesse sentido, os resultados também procuram evidenciar como se deu a construção territorial de Curitiba a partir da perspectiva de seus eixos estruturais, e como, diferentes temporalidades e instrumentos resultaram em configurações espaciais específicas.

\section{BIBLIOGRAFIA}

ALLAIRE, J. (2006). Choisir son mode de ville: formes urbaines et transports dans les villes emergentes. Les Cahiers de global chance (Montreuil),21, 66-70.

AUDIRAC, I.; SHERMYEN, A. H. (1994). An evaluation of neotraditional design's social prescription: postmodern placebo or remedy suburban malaise. Jounal os Planning Education and Research (Estados Unidos), 13, 161-173.

BATTY, M. (2013). The new Science of cities. Cambridge: MIT Press.

CARRIÓN, F. (2007). El desafio político de gobernar la ciudad. Revista Nueva Sociedad (América Latina), $212,36-52$.

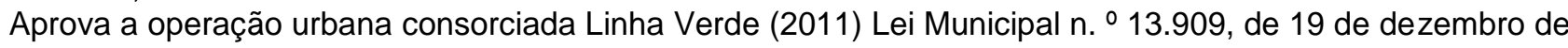
2011. Curitiba.

DEL RIO, V. (1990). Introdução ao desenho urbano no processo de planejamento. São Paulo: PINI.

DUDEQUE, I. T. (2010). Nenhum dia sem uma linha: uma história do urbanismo em Curitiba. São Paulo: Studio Nobel.

FU; Y; ZHANG, X. (2016). Trajectory of urban sustainability concepts: a 35-year bibliometric analysis. Cities (Estados Unidos), 60, 113-123.

GADENS, L. N.; HARDT, L. P. A.; FREY, K. (2012). Das práticas de gestão de grandes projetos urbanos. Saúde e Sociedade (São Paulo), 21, 21-32.

GEHL, J. (2006). La humanización del espacio urbano: la vida social entre los edifícios. Barcelona: Reverté.

GIL, A. C. (2002). Como elaborar projetos de pesquisa. São Paulo: Atlas.

GUALINI, E. (2005). The power of planning. disP, 161, 82-83.

GUNDER, M. (2011). Commentary: is urban design still urban planning? An exploration and response. Journal of Planning Education and Research (Estados Unidos), 31, 2, 184-195.

HANDY, S. (1996). Methodologies for exploring the link between urban form and travel behavior. Transportation Research Part D: Transport and Environment (Estados Unidos), 1, 151-165.

HARDT, L. P. A.; CARVALHO, G. R.; AFONSO, T. M.; HARDT, C. (2008). Grandes Projetos Urbanos: impactos do Plano Serete sobre a morfologia e a paisagem do ambiente construído de Curitiba, Paraná. IV Encontro da Associação Nacional e Pesquisa e Pós-Graduação em Ambiente e Sociedade - ANPPAS, Brasília, 4-6 junho (impresso).

HILDEBRAND, F. (1999). Compact, decentralize dor what? The sustainable debate. In: HILDEBRAND, F (Ed.). Designing the city: towards a more sustainable urban form (23-35). Londres: E\&FN Spon.

IPPUC - Instituto de Pesquisa e Planejamento Urbano de Curitiba (1965). Plano preliminar de urbanismo de Curitiba. Curitiba: IPPUC.

IPPUC - Instituto de Pesquisa e Planejamento Urbano de Curitiba (2014). O planejamento urbano de Curitiba. Curitiba: IPPUC.

IPPUC - Instituto de Pesquisa e Planejamento Urbano de Curitiba (2015). Revisão do Plano Diretor. Curitiba: IPPUC.

JABAREEN, Y. R. (2006). Sustainable urban forms: their typologies, models and concepts. Journal of Planning Education and Research (Estados Unidos), 26, 38-52.

JACOBS, J. (2000). Morte e vida das grandes cidades. São Paulo: Martins Fontes. 
LEME, M.C.da S.(1999). A formação do pensamento urbanístico no Brasil: 1895-1965. In: LEME, M.C.da S.; FERNANDES, A.; GOMES, M.A.F. (Org.) Urbanismo no Brasil 1895-1965. São Paulo: Studio Nobel.

LIMONAD, E. (2015). Muito além do jardim: planejamento ou urbanismo, do que estamos falando? In: COSTA, G. M.; COSTA, H. S. M de; MONTE-MÓR, R. L. M de. (Orgs.). Teorias e práticas urbanas: condições para a sociedade urbana (71-102). Belo Horizonte: C/Arte.

LITMAN, T. (2016). Land use impacts on transport: how land use factors affect travel behavior. Victoria Transport Policy Institute - VTPI (Canadá), ago. 2016.

LUND, H. M.; CERVERO, R.; WILLSON, R.W. (2004). Travel characteristics of transit-focused development in California. Oakland: Bay Area Rapid Transit District and California Departmente of Transportarion.

LUNGO, M. (2004). Grandes proyectos urbanos. San Salvador: Universidad Centroamericana José Simeón Cañas.

LYNCH, K. (1997). A imagem da cidade. São Paulo: Martins Fontes.

MARELONKA, C. (2012). Operações urbanas em São Paulo: ruma a terceira geração? I Congreso Iberoamericano de Suelo Urbano, Buenos Aires, 21-23 novembro (impresso).

MALERONKA, C. (2010). Projeto e gestão na metrópole contemporânea: um estudo sobre as potencialidades do instrumento operação urbana consorciada. 215f. Tese (Doutorado em Arquitetura e Urbanismo) - Faculdade de Arquitetura e Urbanismo, Universidade de São Paulo - USP, São Paulo.

NASAR, J. L. (2003). Does neotraditional development build community? Journal of Planning Education and Research (Estados Unidos), 23, 58-68.

NEWMAN, P. (1996). Reducing automobile dependence. Environment and urbanization, 8, 1, 67-92.

ONU - Organização das Nações Unidas. (2016). Nova agenda urbana. Quito: ONU.

REZENDE, F. C. da. (2002). A reforma do estado em perspectiva comparada. In: NASSUNO, M.; KAMADA, P. H. (Orgs.). Balanço da reforma do Estado no Brasil: a nova gestão pública (223-233). Brasília: MP SEGES.

SANTOS, M. (2008). A natureza do espaço: técnica e tempo, razão e emoção. São Paulo: Editora da Universidade de São Paulo.

SILVA, E. L. da; MENEZES, E. M. (2005). Metodologia da pesquisa e elaboração de dissertação. Florianopólis: Editora da Universidade Federal de Santa Catarina - UFSC.

SOMECK, N.; CAMPOS NETO, C. M.(2005). Desenvolvimento local e projetos urbanos. Arquitextos 059, Texto Especial $\quad 059, \quad$ abr. $2005 . \quad$ Disponível em: <http://www.vitruvius.com.br/revistas/read/arquitextos/05.059/470>. (Consulta: 28/10/2016).

ULTRAMARI, C.; REZENDE, D. A. (2007). Grandes projetos urbanos: conceitos e referenciais. Ambiente Construído (Porto Alegre),7, 1-15.

VILLAÇA, F. (1999). Uma contribuição para a história do planejamento urbano no Brasil.In: DEAK, C.; SCHIFFER, S.R. (Org.). O processo de urbanização no Brasil (169-243). São Paulo: EdUSP.

WALTER, B.; ARKIN, L.; CRENSHAW, R.W. (1992). Sustainable cities: concepts and strategies for eco-city development. Los Angeles: Eco-Home Media.

WILLIAMS, K.; BURTON, E.; JENKS, M. (1996). Achieving the compact city through intensification: na acceptable option. In: WILLIAMS, K.; BURTON, E.; JENKS, M (Ed.). The compact city: a sustainable urban form? (83-96). Londres: E\&FN Spon.

YIFTACHEL, O. (1989). Towards a new typology of urban planning theories. Environment and Planning B: Planning and Design, 16, 1, 23-39.

YIN, R. (1994). Case study research. London: Sage. 